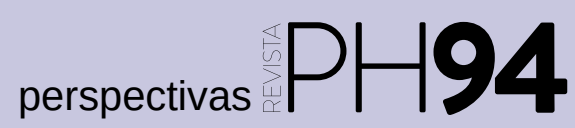

a debate El marco legal para la protección del patrimonio paleontológico. ¿Qué pasa en tu comunidad?

| coordina Eloísa Bernáldez Sánchez

\title{
Faltan técnicos en la gestión del patrimonio paleontológico español
}

Ángela Delgado Buscalioni | Unidad de Paleontología, Dpto. de Biología y Centro para la Integración en Paleobiología (CIPb), Universidad Autónoma de Madrid

URL de la contribución <www.iaph.es/revistaph/index.php/revistaph/article/view/4141>

Las leyes y normativas sobre patrimonio paleontológico de las diferentes comunidades autónomas han frenado lo que los especialistas diagnosticaron como su mayor riesgo: expolios sistemáticos del coleccionismo salvaje. La regulación estimuló también que algunas colecciones privadas fueran salvaguardadas en ámbitos locales dependientes de los ayuntamientos que pasaron a formar parte de colecciones museográficas. Con ello el número de estas aulas o colecciones aumentaron a partir de 1990, algunas con escaso éxito funcionaron temporalmente y su cierre supuso que dichas colecciones dejaran de ser visitables. Sin embargo, otras colecciones fueron debidamente catalogadas y gestionadas, sobre todo en aquellas comunidades con normativas más responsables que sistematizaron las tareas y los perfiles técnicos adecuados para la gestión de su patrimonio como sucede, por ejemplo, en Cataluña (véase el Convenio Colectivo del Sector de la Arqueología y Paleontología en Cataluña).

Las responsabilidades en la gestión del patrimonio son muy desiguales en las diferentes comunidades autónomas de España. Un trabajo reciente (DELVENE; VEGAS; JIMÉNEZ et ál., 2018), en la revista Geoheritage, pone de manifiesto las deficiencias que tiene la gestión de nuestro patrimonio, indicando que las administraciones han de procurar que las colecciones han de ser gestionadas por técnicos formados en paleontología y que los centros donde se salvaguarde el material han de reunir unos requisitos físicos, de catalogación y documentación que garanticen la preservación, sean visitables y se permita el estudio de las colecciones de fósiles. Entre las recomendaciones que plantean, los autores indican que los propios investigadores tendrían que exigir que estas condiciones se cumpliesen o bien depositar el material en el lugar donde consideren sea el más adecuado para su salvaguarda.

La normativa y regulación del patrimonio, al considerar todos los aspectos relativos a su gestión (desde la extracción del material hasta su depósito en los museos), no solo debe contemplar los supuestos legales de conservación sino que debería invertir en la formación de técnicos que desarrollen todas las líneas de investigación implícitas en la gestión del patrimonio: inventarios, sistemas y programas de gestión, divulgación y difusión. Ello supondría la creación de un cuerpo especializado sensible capaz de atender las notificaciones de los hallazgos de ciudadanos y de coordinar con los especialistas todos aquellos aspectos sobre la clasificación, catalogación, valoración y diagnóstico de los inventarios. El patrimonio es un sistema complejo que requiere de la coordinación entre varios agentes sociales: la administración, los científicos y ciudadanos. Para que el patrimonio se convierta en un recurso y tenga una dimensión cultural requiere de personal con dedicación permanente en los museos en donde el patrimonio histórico se salvaguarde y se difunda.

\section{BIBLIOGRAFÍA}

- DELVENE, G.; VEGAS, J.; JIMÉNEZ, R.; RÁBANO, I.; MENÉNDEZ, S. (2018) From the Field to the Museum: Analysis of Groups-Purposes-Locations in Relation to Spain's Moveable Palaeontological Heritage. Geoheritage <https://doi. org/10.1007/s12371-018-0290-3> 